View Article Online / Journal Homepage / Table of Contents for this issue FRANKLAND AND GRAHAM ON THE ACTION OF

\title{
LXVIII.-On the Action of Organo-zinc Compounds upon Nitriles and their Analogues. (Second Notice.)
}

\author{
By E. Frankland, F.R.S., and C. Colborne Graham, A.I.C.
}

\section{Action of Zinc-ethyl on Cyanogen.}

As eight-ounce boiling-flask was inverted over mercury, and a bent glass tube, connected by means of caoutchouc tubing with a Bunsen's pump, was passed up through the mercury so as almost to touch the bottom of the inverted flask. The caoutchonc tabing could be closed by a clip. By means of the Bunsen pump, which was kept in action during the experiment, the mercury was raised almost to the top of the tube, and the clip was then closed. Carbonic anhydride was passed into the flask so as to half fill it, after which 25 grams of zincethyl were introduced. The carbonic anhydride having been drawn off by the pump, cyanogen gas, generated from mercuric cyanide, was passed in, when rapid absorption took place, accompanied by a rise of temperature. The absorption slackened from time to time, owing to the accumulation of a quantity of an indifferent gas, principally ethylic hydride, the formation of which is due to a trace of hydrocyanic acid in the cyanogen. As soon as this gas began to fill the flask the clip was opened, by which means the gas was instantaneously removed, and the absorption proceeded as at first. A strong empty bottle, which acted as a vacuum chamber, was interposed between the clip and the pump. Care was taken to avoid a too great rise of temperature. As the reaction proceeded, the contents of the flask became pasty and of a reddish-brown colour, and by the time the absorption had ceased, the zinc-ethyl had been converted into a solid mass. It was impossible to get rid of the last trace of zinc- 
ethyl, as the solid substance enclosed it, and prevented it from being acted upon.

The flask was then removed from the mercury, and having been attached to a condenser, was heated in an oil-bath to $120^{\circ}$. About 4 c.c. of a colourless liquid containing a trace of zinc-ethyl were obtained. The zinc-ethyl was got rid of by connecting the flask containing the liquid with a gas holder of oxygen, and agitating the liquid with this gas as long as any absorption took place, the flask being kept cool by immersion in ice and water. The liquid was then redistilled, and it boiled steadily at $96^{\circ}$. The following results were obtained by combustion :-

0.1949 gram gave 0.4685 gram carbonic anbydride and 0.1624 gram water.

\begin{tabular}{|c|c|c|c|}
\hline \multirow[b]{2}{*}{$\mathrm{C}_{3}$} & \multicolumn{2}{|c|}{$\begin{array}{l}\text { Calculated for } \\
\qquad \mathrm{C}_{3} \mathrm{H}_{5} \mathrm{~N}\end{array}$} & Found. \\
\hline & $\overparen{36}$ & $65 \cdot 45$ & 65.57 \\
\hline $\mathrm{H}_{5} \ldots \ldots$ & 5 & $9 \cdot 09$ & $9 \cdot 26$ \\
\hline N..... & 14 & $25 \cdot 46$ & - \\
\hline & & $100 \cdot 00$ & \\
\hline
\end{tabular}

The substance had thus, as regards carbon and hydrogen, the percentage composition of propionitrile, and to this compound its boiling point, odour, and other properties also. pointed. No odour of the normal cyanide could be perceived.

As a further proof, a portion of the liquid was saponified with alcoholic potash, and the potassic propionate thus obtained was distilled with dilute sulphuric acid. The distillate of dilute propionic acid was converted into the barium salt, of which a barium determination gave the following result:-

0.4015 gram barium salt dried at $130-140^{\circ}$ gave 0.3292 gram baric sulphate, corresponding to 0.1936 gram barium.

$$
\begin{aligned}
& \text { Calculated for } \\
& \mathrm{C}_{6} \mathrm{H}_{10} \mathrm{O}_{4} \mathrm{Ba} \text {. Fonnd } \\
& \text { Barium in } 100 \text { parts..... } 48 \cdot 41 \quad 48 \cdot 22
\end{aligned}
$$

The solid residue remaining after the removal of the propionitrile consisted almost entirely of zincic cyanide. On the addition of water it evolved very little gas, showing the absence of zinc-monethyl compounds. Boiling alcohol extracted from it a small quantity of a brownish oil. The solid matter remaining after treatment with alcohol dissolved completely in hydrochloric acid, evolving a strong

VOL. XXXVII. 
odour of hydrocyanic acid. The action of zinc-ethyl on cyanogen may therefore be expressed by the equation-

$$
2\left\{\begin{array}{l}
\mathbf{C N} \\
\mathbf{C N}
\end{array}+\mathbf{Z n E t}_{2}=2 \mathrm{Et}(\mathrm{CN})+\mathbf{Z n}(\mathrm{CN})_{2} .\right.
$$

It is noteworthy in this reaction that a separation of carbon from carbon accompanied by a simultaneous union of carbon to carbon occurs, both processes taking place at ordinary temperatures. In other respects the action is strictly analogous to that discovered by Gal (Annalen, 147, 126), in which by the action of cyanic chloride on zinc-ethyl, propionitrile and zincic chloride were obtained. 